\title{
A neuropsychological study of active amateur boxers
}

\author{
N BROOKS, ${ }^{*}$ G KUPSHIK, ${ }^{*}$ L WILSON, $\dagger$ S GALBRAITH, $\ddagger$ R WARD \\ From the Glasgow University Department of Psychological Medicine, ${ }^{*}$ Glasgow; Department of Psychology, $\dagger$ \\ University of Stirling, Stirling; Department of Neurosurgery, $\ddagger$ Institute of Neurological Sciences, Southern \\ General Hospital, Glasgow, UK
}

SUMMARY Neuropsychological examinations were carried out on 29 amateur boxers and 19 controls matched for age, ethnicity, and education. There was no evidence of significantly impaired performance in the boxers. Within the boxing group, a variety of features of boxing history were examined as possible predictors of cognitive performance (such as number of knockouts, duration of boxing). No feature was a significant predictor of lower cognitive performance.

The relationship between boxing and brain damage remains controversial. The evidence suggests that professional boxers may suffer brain damage as a result of the sport, and the greater the number of fights, the greater the likelihood of damage. ${ }^{1}$ Supporters of amateur boxing, however, emphasise the differences between amateur and professional boxing; there are fewer rounds of shorter duration, with fights stopped more quickly if one of the participants is in trouble. Furthermore, evidence concerning the neurological and neuropsychological effects of amateur boxing is equivocal. A study of 53 Danish former amateur boxers ${ }^{2}$ found no evidence of impairment, but the neuropsychological procedures used in that study may not have been adequate to detect subtle cognitive impairments. Other studies ${ }^{34}$ suggest that some amateur boxers may show subtle signs of brain damage. The second of these studies, although clearly identifying a subgroup of active amateur boxers with clinical, electroencephalographic, and neuropsychological evidence of abnormal brain function, failed to incorporate a normal control group. The present study was designed, therefore, to rectify this deficit by examining the neuropsychological status of active amateur boxers and matched non-boxing control subjects.

\section{Method}

\section{Subjects}

The population from which the sample of 29 subjects was drawn comprised 75 amateur boxers training at several Amateur Boxing Association (ABA) affiliated clubs in Lon-

Address for reprint requests: Professor Neil Brooks, Glasgow University Department of Psychological Medicine, 6 Whittinghaeme Gardens, Great Western Road. Glasgow G12 0AA, Scotland, UK.

Received 26 September 1986 and in revised form 31 December 1986. Accepted 5 January 1987 don. Of the 75 approached and asked to take part, 25 (33\%) who originally agreed to participate failed to attend for assessment; $19(25 \%)$ were unwilling to be assessed. Two (3\%) failed to meet assessment criteria. Twenty nine boxers were tested, giving a $39 \%$ sample.

The 29 were compared with 19 control subjects matched for age, ethnicity, and educational level. Only six controls refused to take part, giving a $75 \%$ sample. To increase the accuracy of matching, 11 of the controls were prospective amateur boxers (training without sparring). The prospective amateurs were attending the boxing clubs from which the boxers themselves were chosen. The remaining eight controls comprised seven friends of boxers who were attending a boxing club but taking no part in its activities, or in one case was a volunteer from a Job Centre adjacent to the Headquarters of the research. All subjects were aged between 15 and 27 years, and had no previous history of alcohol or drug abuse, or head injury of sufficient severity to require admission to hospital. Demographic details of subjects are shown in table 1 , and important details of the boxers are shown in table 2 .

Table 1 Details of subjects and controls

\begin{tabular}{lllllll}
\hline & \multicolumn{3}{l}{ School leaving age $(y r)$} & & \multicolumn{2}{l}{ Age $(y r)$} \\
\cline { 2 - 3 } & $N$ & Mean & $S D$ & & Mean & $S D$ \\
\hline Boxers & 29 & 16.0 & 3.1 & & 21.0 & 3.1 \\
Controls & 19 & 16.4 & 1.0 & & 21.0 & 3.0 \\
\hline
\end{tabular}

Table 2 Boxing career details

\begin{tabular}{llcrr}
\hline Career features & Minimum & Maximum & Mean & SD \\
\hline Wins & 1 & 63 & $18 \cdot 3$ & $15 \cdot 4$ \\
Losses & 0 & 32 & $8 \cdot 6$ & $7 \cdot 4$ \\
Stoppages & 0 & 3 & $0 \cdot 9$ & $0 \cdot 9$ \\
Bouts & 2 & 96 & $26 \cdot 2$ & $22 \cdot 2$ \\
Length of career (yr) & 1 & 13 & 5 & $3 \cdot 1$ \\
Sparring frequency & & & & \\
$\quad$ (weekly) & 1 & 4 & $2 \cdot 8$ & $0 \cdot 7$ \\
Weight (kg) & 32 & 82 & $68 \cdot 4$ & $15 \cdot 4$ \\
\hline
\end{tabular}


Table 3 Cognitive test procedures (appropriate references are in parenthesis)

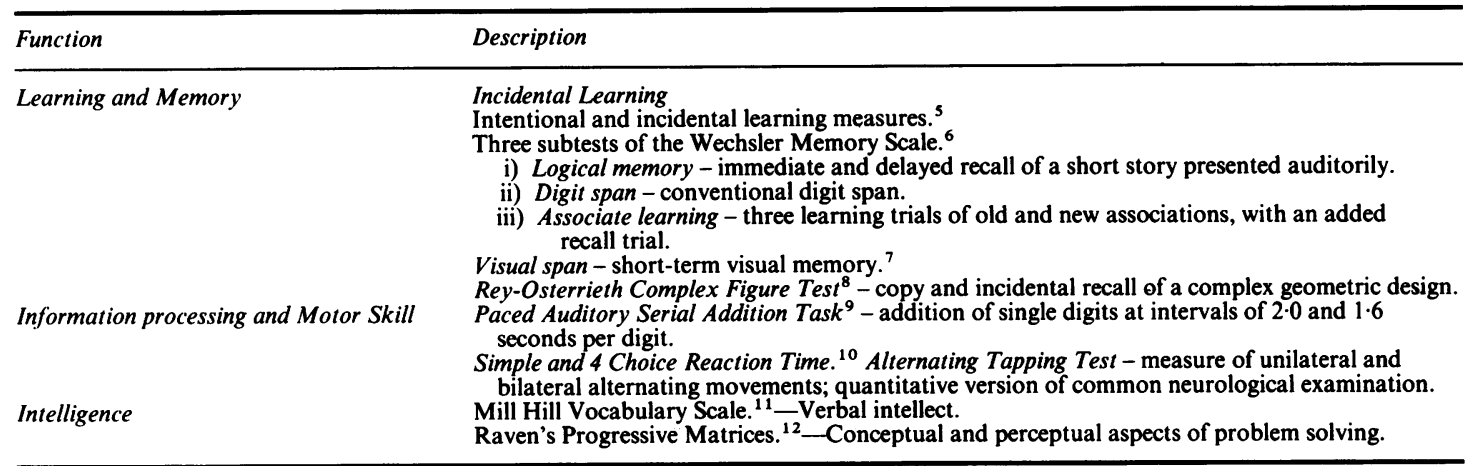

\section{Procedure}

A list of ABA affiliated clubs, and permission to approach the clubs was obtained from the Secretary of the ABA. Following initial interview with each potential subject at the boxing club, a test battery was administered at a second session to those meeting selection criteria.
Test materials (table 3 )

A range of cognitive procedures was included. Test selection was dictated by the assumption that brain damage, if present, would be similar to that found in minor closed head injury. Therefore, verbal and visuospatial memory, attention, information processing and motor function, and intellectual abilities were all assessed. Further details of tests may be obtained from the authors (JTLW or DNB).

Table 4 Summary of comparisons of boxers and controls on cognitive tests

\begin{tabular}{|c|c|c|c|c|c|c|}
\hline \multirow[b]{2}{*}{ Test } & \multicolumn{2}{|l|}{ Boxer } & \multicolumn{2}{|c|}{ Control } & \multirow[b]{2}{*}{$t$} & \multirow[b]{2}{*}{$p$} \\
\hline & $M$ & $S D$ & $M$ & $S D$ & & \\
\hline $\begin{array}{l}\text { Incidental learning } \\
\text { Intentional learning } \\
\text { Logical memory - Immediate } \\
\quad \text { Delayed } \\
\text { Associate learning - old }\end{array}$ & $\begin{array}{r}2 \cdot 9 \\
5 \cdot 2 \\
10 \cdot 9 \\
10 \cdot 7\end{array}$ & $\begin{array}{l}1 \cdot 4 \\
1.0 \\
2 \cdot 4 \\
3 \cdot 0\end{array}$ & $\begin{array}{r}2 \cdot 8 \\
5 \cdot 5 \\
12 \cdot 9 \\
13 \cdot 1\end{array}$ & $\begin{array}{l}1 \cdot 2 \\
1 \cdot 3 \\
2 \cdot 7 \\
3 \cdot 0\end{array}$ & $\begin{array}{l}0 \cdot 19 \\
0 \cdot 68 \\
2 \cdot 53 \\
2 \cdot 60\end{array}$ & $\begin{array}{l}\text { NS } \\
\text { NS } \\
<0.05 \\
<0.05\end{array}$ \\
\hline $\begin{array}{l}\text { associations } \\
\text { Associate learning - new }\end{array}$ & $15 \cdot 5$ & $2 \cdot 0$ & $15 \cdot 5$ & $2 \cdot 5$ & 0.01 & NS \\
\hline $\begin{array}{l}\text { associations } \\
\text { Digit span - (forward and } \\
\text { reversed) }\end{array}$ & $11 \cdot 3$ & $1 \cdot 3$ & $11 \cdot 0$ & $1 \cdot 4$ & 0.57 & NS \\
\hline $\begin{array}{l}\text { Visual span } \\
\text { Rey Figure - copy } \\
\text { Immediate recall }\end{array}$ & $\begin{array}{l}12 \cdot 3 \\
35 \cdot 5 \\
21 \cdot 7\end{array}$ & $\begin{array}{l}3 \cdot 5 \\
0 \cdot 9 \\
6 \cdot 4\end{array}$ & $\begin{array}{l}13 \cdot 8 \\
34 \cdot 9 \\
20 \cdot 7\end{array}$ & $\begin{array}{l}4 \cdot 1 \\
1 \cdot 8 \\
5 \cdot 9\end{array}$ & $\begin{array}{l}1 \cdot 38 \\
1 \cdot 27 \\
0 \cdot 54\end{array}$ & $\begin{array}{l}\text { NS } \\
\text { NS } \\
\text { NS }\end{array}$ \\
\hline $\begin{array}{l}\text { PASAT (slow presentation) } \\
\text { Total score } \\
\text { Longest string recalled } \\
\text { PASAT (fast presentation) }\end{array}$ & $\begin{array}{l}40 \cdot 3 \\
11.9\end{array}$ & $\begin{array}{r}10 \cdot 1 \\
9 \cdot 0\end{array}$ & $\begin{array}{l}38 \cdot 0 \\
11 \cdot 4\end{array}$ & $\begin{array}{l}9 \cdot 7 \\
7 \cdot 2\end{array}$ & $\begin{array}{l}0.76 \\
0.18\end{array}$ & $\begin{array}{l}\text { NS } \\
\text { NS }\end{array}$ \\
\hline $\begin{array}{l}\text { Total score } \\
\text { Longest string recalled } \\
\text { Reaction time ( } \mathrm{m} \mathrm{sec})\end{array}$ & $\begin{array}{r}34 \cdot 6 \\
8 \cdot 3\end{array}$ & $\begin{array}{l}8 \cdot 6 \\
6 \cdot 2\end{array}$ & $\begin{array}{r}34 \cdot 4 \\
7 \cdot 6\end{array}$ & $\begin{array}{l}6 \cdot 2 \\
3 \cdot 9\end{array}$ & $\begin{array}{l}0 \cdot 12 \\
0 \cdot 38\end{array}$ & $\begin{array}{l}\text { NS } \\
\text { NS }\end{array}$ \\
\hline $\begin{array}{l}\text { Simple - decision time } \\
\text { movement time } \\
\text { Choice }- \text { decision time } \\
\text { movement time } \\
\text { Tapping }-3 \text { trials }\end{array}$ & $\begin{array}{l}253 \cdot 7 \\
163 \cdot 9 \\
278 \cdot 5 \\
170 \cdot 8\end{array}$ & $\begin{array}{l}33 \cdot 3 \\
44 \cdot 7 \\
36 \cdot 1 \\
59 \cdot 0\end{array}$ & $\begin{array}{l}253 \cdot 8 \\
178 \cdot 3 \\
290 \cdot 0 \\
175 \cdot 4\end{array}$ & $\begin{array}{l}23 \cdot 1 \\
35 \cdot 7 \\
28 \cdot 3 \\
36 \cdot 0\end{array}$ & $\begin{array}{l}0.01 \\
1.21 \\
1.21 \\
0.33\end{array}$ & $\begin{array}{l}\text { NS } \\
\text { NS } \\
\text { NS } \\
\text { NS }\end{array}$ \\
\hline $\begin{array}{l}\text { Left hand } \\
\text { Right hand } \\
\text { Synchronous tapping }\end{array}$ & $\begin{array}{l}188 \cdot 4 \\
218 \cdot 2\end{array}$ & $\begin{array}{l}27.9 \\
35 \cdot 9\end{array}$ & $\begin{array}{l}185 \cdot 1 \\
220 \cdot 2\end{array}$ & $\begin{array}{l}24 \cdot 2 \\
21 \cdot 4\end{array}$ & $\begin{array}{l}0.30 \\
0.20\end{array}$ & $\begin{array}{l}\text { NS } \\
\text { NS }\end{array}$ \\
\hline $\begin{array}{l}\text { Left } \\
\text { Right }\end{array}$ & $\begin{array}{l}120 \cdot 0 \\
122 \cdot 1\end{array}$ & $\begin{array}{l}29 \cdot 1 \\
27 \cdot 7\end{array}$ & $\begin{array}{l}118 \cdot 8 \\
118 \cdot 8\end{array}$ & $\begin{array}{l}21 \cdot 8 \\
22 \cdot 1\end{array}$ & $\begin{array}{l}0 \cdot 10 \\
0 \cdot 40\end{array}$ & $\begin{array}{l}\text { NS } \\
\text { NS }\end{array}$ \\
\hline $\begin{array}{l}\text { Intelligence } \\
\text { Progressive Matrices/IQ } \\
\text { Vocabulary Scale/IQ }\end{array}$ & $\begin{array}{r}106 \cdot 8 \\
98 \cdot 8\end{array}$ & $\begin{array}{l}10 \cdot 1 \\
10 \cdot 0\end{array}$ & $\begin{array}{l}82 \cdot 7 \\
84 \cdot 6\end{array}$ & $\begin{array}{l}5 \cdot 3 \\
4 \cdot 2\end{array}$ & $\begin{array}{l}2 \cdot 62 \\
1 \cdot 31\end{array}$ & $\mathrm{p}_{\mathrm{NS}}<0.05$ \\
\hline
\end{tabular}


Results

The results were first analysed by comparing the boxers with the controls by means of simple $t$ tests. Secondly, within the sample of boxers, relationships between boxing features (duration of boxing, the number of bouts, etc) and cognitive status were assessed.

\section{Comparison of boxers and controls (table 4)}

The results of the $t$ tests comparing boxers and controls are shown in table 4 . The 10 separate cognitive procedures yielded 24 individual measures of performance, only three of which showed significant differences at $p<0.05$. Not only were there few significant differences, but the pattern of results did not suggest that boxers consistently scored below controls. Controls were better on six of the measures; boxers on 12; and on six measures, the means did not differ by more than two decimal places.

There is a potential problem in interpreting results, in that whereas controls were not significantly different from boxers on verbal intelligence (Mill Hill Vocabulary Scale), they showed a significantly lower score $(p<0.05)$ on performance aspects of intelligence (Raven's Progressive Matrices). In view of this, the boxer-control comparisons were repeated, but as an analysis of covariance by comparing the mean scores of the two groups following covariation of the Matrices IQ. This procedure had very little effect except on two of the PASAT measures (number correct and longest string recalled at fast presentation rate). On these measures, controls became significantly better $(\mathrm{p}<0.01)$.

\section{Within-boxer effects}

A number of within-boxing effects could influence cognitive status; for example, the number of knockouts, the duration of amateur boxing, the age and weight at which the boxer competes, numbers of wins and losses, and numbers of bouts in which the referee has stopped the contest. Boxers were therefore categorised in terms of high or low measures on each of these variables (the split was taken at the fiftieth percentile), and $t$ tests were computed comparing the two resulting subgroups. On no comparisons were there significant differences. Similarly when correlations were computed between cognitive variables and appropriate boxing variables (length of time as an amateur, numbers of wins and losses, etc.) no significant effects were found.

\section{Discussion}

In this study, there was no consistent pattern of cognitive deficit in the boxers. Furthermore, there were no significant relationships between various measures of intensity or effectiveness of amateur boxing career and neuropsychological status. Before considering giving amateur boxing a clean bill of health, possible reasons for this lack of significance must be considered.

Firstly, it may indeed be the case that carefully controlled duration amateur boxing is indeed neuropsychologically safe. There is no doubt that the ABA is very concerned about safety, and referees stop fights extremely quickly at the first sign of distress on the part of one of the boxers. Furthermore, in the carefully supervised clubs studied, if any boxer receives a severe blow to the head during sparring he is immediately stopped from boxing and from sparring for 28 days. The temporary termination of sparring is an important feature, as in less carefully controlled situations, boxers may spar frequently and unsupervised. This appears to have been the case with at least some of the boxers studied by McLatchie et $a l^{4}$ and that may be one factor in determining the presence of a subgroup of apparently damaged boxers in that study.

A further reason for the failure to find any significant differences between boxers and controls may be methodological problems in the study. Such problems could include the use of inappropriate tests, or inappropriately chosen or inaccurately matched subjects and controls. The tests were chosen on the assumption that any brain damage in amateur boxing would be of the sort found in minor concussion, representing deficits largely in information processing and memory. We are, therefore, confident that the measures were adequately chosen.

We have less confidence about the representative nature of the sample, in that the boxers were more intellectually able than the controls. However, analysis of covariance failed to demonstrate any major or consistent effect here.

A further point to bear in mind is that the sample of boxers studied represented only a $39 \%$ sample of the population initially chosen. Those who refused to take part may have had a subjective awareness of impairments, and refusers must represent a high priority for research before concluding that amateur boxing is no more dangerous than other contact sports. However, against the possibility of a subjective awareness of impairment is the fact that our boxers were if anything more rather than less successful, with an 18/8 ratio of wins to losses. The range of duration of boxing career was long (1-13 years), and this must raise the question of how long one can box before there is evidence of damage. In our study, there was no relationship between cognitive status and duration of amateur career, but there is obviously need for a longitudinal study of amateur boxers, or if 


\section{0}

that is impractical, studies of amateur boxers with long boxing histories. This is particularly important in view of the pilot results from McLatchie et $a l^{4}$ which identified a subgroup of boxers with a long history who had neurological and neuropsychological impairments.

In conclusion, there is no evidence from the present study that well controlled amateur boxing produces neuropsychological abnormalities indicating brain damage.

This study was funded by an award from the Greater London Council.

\section{References}

1 Roberts AH. Brain Damage in Boxers. London: Pitman, 1969.

2 Thomassen A, Juul-Jensen P, de Fine Olivarius B, Braemer J, Christensen AL. Neurological, electroencephalographic and neuropsychological examination of 53 former amateur boxers. Acta Neurol Scand 1979;60:352-62.

3 Kaste M, Vilkki J, Sainis K, Kuume T, Katevuo K, Meurala $\mathrm{H}$. Is chronic brain damage in boxing a haz-
Brooks, Kupshik, Wilson, Galbraith, Ward ard of the past? Lancet 1982;ii:1186-8.

4 McLatchie G, Brooks N, Galbraith S, et al. Clinical neurological examination, neuropsychology, electroencephalography and computed tomographic head scanning in active amateur boxers. J Neurol Neurosurg Psychiatry 1987;50:96-9.

5 Hockey GRH, Hamilton P. Arousal and information selection in short term memory. Nature 1970;226: 766-7.

6 Wechsler D. A standardised memory scale for clinical use. J Psychol 1945;19:870-95.

7 Wilson JTL, Scott JM, Power KG. Developmental differences in the span of visuo memory pattern. $\mathrm{Br} \mathrm{J}$ Dev Psychol 1987 (in press).

8 Rey A. L'examen psychologique dans les cas d'encephalopathie traumatique. Archives de Psychologie 1942;28:112.

9 Gronwall D, Wrightson P. Cumulative effect of concussion. Lancet 1976;ii:995-7.

10 Van Zomeren AH, Deelman BG. Long-term recovery of visual reaction time after closed head injury. $J$ Neurol Neurosurg Psychiatry 1978;41:452-7.

11 Raven JC. Guide to the Standard Progressive Matrices. London: WK Lewis, 1980.

12 Raven JC. Extended Guide to the Mill Hill Vocabulary Scale with the Progressive Matrices Scale. London: HK Lewis, 1982. 